\title{
Conflicts of interest and expertise of independent commenters in news stories about medical research
}

\author{
Michael T.M. Wang, Andrew Grey MBChB MD, Mark J. Bolland MBChB PhD
}

Cite as: CMAJ 2017 April 18;189:E553-9. doi: 10.1503/cmaj.160538

See related article at www.cmaj.ca/lookup/doi/10.1503/cmaj.161206

\begin{abstract}
BACKGROUND: Media coverage of medical research influences the views and behaviours of clinicians, scientists and members of the public. We examined how frequently commenters in news stories about medical research have relevant expertise and have academic and financial conflicts, how often such conflicts are reported and whether there are associations between the conflicts and the disposition of the comments toward the findings of the source research.
\end{abstract}

METHODS: We analyzed 104 independent comments in news stories on original clinical research published in high-impact medical journals from Jan. 1 to Mar. 31, 2013, and 21 related journal editorials.
Main outcomes were prevalence of relevant academic and clinical expertise, prevalence and reporting of academic and financial conflicts of interest, and disposition of comments toward study findings.

RESULTS: Only 1 in 6 news stories included independent comments. Overall, $25 \%$ of commenters and $0 \%$ of editorialists had neither relevant academic nor clinical expertise ( $p=0.007$ ). Among the 104 comments, an academic conflict of interest was present for 56 (54\%), of which 25 (45\%) were reported in the news stories. A financial conflict of interest was present for $33(32 \%)$ of the comments, of which 11 (33\%) were reported. When commenters' conflicts of interest were congruent with the findings of the source research, $97 \%$ and $93 \%$ of comments associated with academic and financial conflicts of interest, respectively, were favourably disposed toward the research. These values were $16 \%$ and $17 \%$, respectively, when the conflicts of interest were not congruent with the research findings.

INTERPRETATION: Independent commenters in new stories about medical research may lack relevant academic or clinical expertise. Academic or financial conflicts of interest were frequently present among independent commenters but infrequently reported, and were often associated with the disposition of comments about the source research.

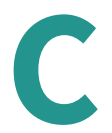

onflicts of interest can compromise the integrity and objectivity of professional opinions and judgments and there are increasing calls for more independent voices in media coverage of health. ${ }^{1-6}$ Two important conflicts of interest are financial and academic. ${ }^{7}$ Academic (intellectual) conflicts of interest, defined as "academic activities that create the potential for an attachment to a specific point of view that could unduly affect an individual's judgment about a specific recommendation," may be less easily identified than financial conflicts of interest but are equally influential. ${ }^{9,10}$ In practice, financial and academic conflicts of interest often overlap or intersect. ${ }^{11}$ Disclosure of financial conflicts of interest is widely encouraged in various academic settings, including conference presentations, journal publications and clinical guideline development., ${ }^{7,8}$ Disclosure of academic conflicts of interest has been recommended as part of guideline development. ${ }^{8,11}$

Media coverage of medical research influences the views of clinicians, scientists and members of the public, and consequently can affect health behaviours. ${ }^{12-15} \mathrm{Health}$ journalism organizations recommend that journalists preparing news stories about medical research seek comments from individuals or organizations not directly associated with the source research or the publishing journal, and report conflicts of interest of contributors to a news story. ${ }^{6}$

In this study, we examine how frequently commenters in news stories about medical research have relevant expertise, how often 
they have academic and financial conflicts, how often such conflicts are reported and whether there are associations between the conflicts and the disposition of the comments toward the findings of the source research.

\section{Methods}

\section{Collation of study documents}

Previously, we assembled a data set of clinical research publications in the top 7 general or internal medicine journals by impact factor, and associated media coverage. ${ }^{16,17}$ We searched MEDLINE for articles reporting original research with a clinical outcome that were published between Jan. 1 and Mar. 31, 2013, in the New England Journal of Medicine, the Journal of the American Medical Association, The Lancet, PLoS Medicine, JAMA Internal Medicine, the British Medical Journal and Annals of Internal Medicine. To identify news stories generated by the source articles, we searched Factiva (https://global.factiva.com), a global news database of more than 30000 information sources, including newspapers, journals, magazines, and television and radio transcripts. We used search terms that included the journal of publication and outcomes investigated, with a time limit of 2 months after online or print publication.

For the current analysis, we considered source articles to be those reporting original research with a clinical outcome that generated 1 or more news stories within 2 months after publication. Two of us (M.W. and A.G.) independently extracted comments from the news stories that were attributed to independent commenters (defined as commenters other than the study authors, study sponsors or journal editorialists who were not involved in development or marketing of the intervention assessed in the source research).

If an independent commenter provided comments on more than 1 source article, we reviewed the relevant articles and included each comment in the analysis if the articles did not overlap, because we recognized that commenters could have expertise and conflicts of interest relevant to one piece of research but not another. Independent commenters who were spokespersons for advocacy organizations were assessed as individuals in the primary analysis; in a secondary analysis, we assessed financial conflicts of interest of the organization.

For a comparison data set of comments, we collated journal editorials accompanying the source articles and analyzed them in the same fashion as the independent comments. If an editorial was written by more than 1 author, we assessed the authors as a single entity ("the editorialist").

\section{Assessments}

For the assessment of expertise, presence and reporting of conflicts of interest, strength of financial conflicts and disposition of comments, 2 investigators conducted independent assessments. If consensus could not be reached, a third investigator provided an assessment, and the majority view was recorded.

\section{Assessment of expertise}

Independent commenters or editorialists were defined as clinical experts if they practised in a discipline directly relevant to the source article. They were considered academic experts if they had

Box 1: Examples of implicit and explicit reporting of academic conflicts of interest

Research topic

Trial of fecal transplant for treatment of Clostridium difficile $^{18}$

Study of association between obesity and vitamin D status ${ }^{19}$

Trial of acupuncture for seasonal rhinitis ${ }^{20}$

\section{Comment/conflict}

"The study is very exciting," said Dr. ... who ... is a vocal proponent of fecal transfusions and has performed them for 4 years. "I hope this will help to change minds. Those of us who do them know they're effective, and to our patients, it's like a miracle."21

“... a quote from Professor ... from the National Obesity Forum. He said that 'food intake and genetics all play a part in obesity - but this research is a reminder that physical activity, like walking the dog or going for a run out in the sunshine, shouldn't be forgotten and can help correct both weight and lack of vitamin D.' '"22

Editorialists are proponents and practitioners of acupuncture ${ }^{23}$

\section{Rationale}

Reporting

Proponent of fecal transplants

Physician specializing in obesity medicine

Proponent of acupuncture

\section{Explicit} Implied

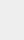

Not declared

\section{Box 2: Examples of strengths and reporting of financial conflicts of interest}

\section{Research topic}

Study of association between fitness levels and dementia ${ }^{24}$

Trial of novel agent for heart failure ${ }^{25}$

Trial of robotically assisted versus conventional surgery ${ }^{26}$

\section{Conflict}

Commenter has written books on preventing Alzheimer disease ${ }^{27}$

Editorialist consults for companies that are potential competitors ${ }^{28}$

Commenter uses robotic surgery in clinical practice $^{29}$

$\begin{array}{cc}\text { Strength } & \text { Reporting } \\ \text { High } & \text { Not declared } \\ \text { Low } & \text { Explicit } \\ \text { High } & \text { Implied }\end{array}$


coauthored 5 or more papers during the period 2008-2012 that assessed either the intervention/exposure or main outcome of the source article, as reported in the abstract of the source article.

Details of clinical practice were obtained independently by 2 investigators (M.W. and M.B.) from the news story or editorial. If the necessary information was not reported, a Google search that included personal and institutional websites was undertaken by 1 investigator (M.B.) and the results checked by the other (M.W.). Clinical expertise was then classified independently by the same investigators.

To assess academic expertise, the 2 investigators independently searched Scopus (M.B.) and PubMed (M.W.) to collate research articles coauthored by each independent commenter or editorialist during the period 2008-2012. They identified articles relevant to the source research. The same 2 investigators independently assessed whether each commenter met the definition of academic expert.

\section{Assessment of conflicts of interest}

We used the International Committee of Medical Journal Editors' definition of a conflict of interest: "When professional judgment concerning a primary interest (such as patients' welfare or the validity of research) may be influenced by a secondary interest (such as financial gain)." "We considered a financial conflict of interest to exist when there was evidence of financial connection(s) between an independent commenter or editorialist and any entity with commercial interests in the outcome of the source research. We considered an academic conflict of interest to exist when there was evidence of a consistent, unidirectional advocacy position relevant to the source research.

Two investigators (M.W. and M.B.) independently assessed each news story and editorial for the reporting of a conflict of interest and whether the reporting was explicit or implicit. Reporting of a conflict of interest was considered explicit when it was clearly evident that the commenter's views could potentially be influenced by financial or academic interests, activities or beliefs (Box 1).

To identify conflicts of interest not disclosed in the news stories and editorials, the same 2 investigators independently searched for disclosure statements in up to 20 publications coauthored by each independent commenter or editorialist immediately before publication of the source article. They searched the Internet using terms that included each commenter's name and institution, and terms relevant to the subject of the comment. Each investigator independently graded the financial conflicts of interest as high, moderate or low, based on their nature, importance and potential impact (Box 2).

To identify relevant financial conflicts of interest of organizations represented by independent commenters but not disclosed in the news stories, one investigator (A.G.) searched the organizations' websites to obtain a list of sponsors, and a second investigator (M.B.) reviewed the extracted data.

\section{Assessment of disposition toward research findings}

Two investigators (M.W. and M.B.) independently classified the disposition of each comment (from an independent commenter or an editorialist) toward the findings of the source article as positive, mixed/neutral or negative.

\section{Statistical analysis}

We determined the sample size pragmatically by the number of clinical studies and associated news stories published during the first quarter of 2013. Statistical analyses were performed with the use of GraphPad Prism 6.02 (GraphPad Software Inc.). Categorical data were compared with the use of the $\chi^{2}$ or Fisher exact test. Continuous variables were analyzed with the use of the Wilcoxon rank-sum test. We evaluated interassessor agreement using the Cohen $\kappa$ coefficient, the proportion of agreement between 2 assessors, adjusted for chance. ${ }^{30}$ All tests were 2 -tailed, and we considered a $p$ value of less than 0.05 to be significant.

\section{Results}

Of 273 potentially eligible source research articles identified, 131 reported clinical outcomes and generated 1 or more news stories (Figure 1). The 131 articles generated 591 news stories, of which 92 $(16 \%)$ contained comments from independent commenters. The 92 news stories contained 104 comments attributed to 102 independent commenters and were generated by 40 source articles; 21 of these source articles were accompanied by an editorial (Appendix 1, available at www.cmaj.ca/lookup/suppl/doi:10.1503/ cmaj.160538/-/DC1). Eighty-five of the 92 news stories were in the print media, and 9 included comments from more than 1 independent commenter. Two independent commenters each provided comments on 2 source articles. In each case, there was no overlap between the exposures or outcomes in the relevant source articles, so we included each comment in our analysis. We therefore analyzed 104 independent comments and 21 editorial comments;

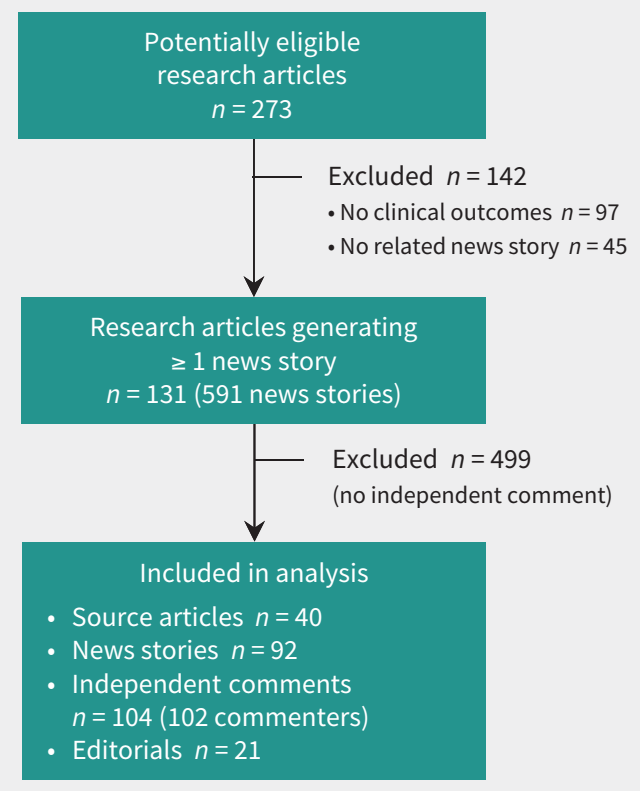

Figure 1: Selection of source research articles published in 7 high-impact general or internal medicine journals between Jan. 1 and Mar. 31, 2013. Media news stories generated in response were identified from Factiva (https://global.factiva.com), a global news database. 
23 of the independent comments were from spokespersons for advocacy organizations.

Interassessor agreement on the presence of expertise, presence and reporting of conflicts of interest, and disposition of comments toward the source research was high (Table 1). ${ }^{31}$ of the assessments, $6 \%-17 \%$ required an assessment by a third investigator.

\section{Expertise}

Table 2 contains the results of assessments of expertise associated with the comments made by the independent commenters and editorialists. Editorialists coauthored more papers than the independent commenters in the 5 years preceding publication of the

\begin{tabular}{|c|c|}
\hline Measure & $\begin{array}{c}\text { Cohen } \kappa \text { coefficient } \\
(95 \% \mathrm{Cl})\end{array}$ \\
\hline Presence of clinical expertise & $0.94(0.87-1.00)$ \\
\hline Presence of academic expertise & $0.86(0.77-0.95)$ \\
\hline Presence of academic conflict of interest & $0.81(0.71-0.91)$ \\
\hline Reporting of academic conflict of interest & $0.79(0.64-0.95)$ \\
\hline Presence of financial conflict of interest & $0.73(0.60-0.86)$ \\
\hline Reporting of financial conflict of interest & $0.66(0.42-0.91)$ \\
\hline Disposition of comments toward source research & $0.68(0.56-0.80)$ \\
\hline
\end{tabular}

source article (median 65, 95\% confidence interval [CI] 52-99, v. $30,95 \% \mathrm{Cl} 20-38 ; p=0.006$ ). Independent commenters were less likely than editorialists to have recently coauthored a study of similar design to that of the source research article (46\% v. 90\%; $p<0.001)$ and more likely to have not published a recent paper relevant to the source research ( $28 \%$ v. $5 \% ; p=0.02)$.

As for expertise, $53 \%$ of the independent commenters were considered to have academic expertise, as compared with $86 \%$ of the editorialists $(p=0.007)$. The proportion with relevant clinical expertise was similar in the 2 groups (56\% of independent commenters and $48 \%$ of editorialists; $p=0.6$ ). Overall, $25 \%$ of the independent commenters had neither academic nor clinical expertise, as compared with none of the editorialists $(p=0.007)$. Of the 26 independent commenters with neither academic nor clinical expertise, 18 were spokespersons for advocacy organizations.

\section{Conflicts of interest}

Figure 2, top panel, shows the prevalence of conflicts of interest. Among the 104 independent comments, an academic conflict of interest was present for 56 (54\%) and a financial conflict of interest for 33 (32\%). Similar results were observed among the 21 editorial comments, with an academic conflict of interest present for $9(43 \%)$ and a financial conflict of interest present for $8(38 \%)$. Of the 33 financial conflicts of interest among the independent comments, 25 (76\%) were rated as high, $1(3 \%)$ as moderate and $7(21 \%)$ as low in strength. Of the 8 financial conflicts of interest among editorialists, 4 (50\%) were high, 1 (13\%) moderate and $3(38 \%)$ low in strength.

Figure 2, lower panel, shows the prevalence of reporting of conflicts of interest. Among the independent comments, 25 (45\%) of

\section{Table 2: Expertise associated with independent comments and journal editorials}

\section{No. $(\%)$ of comments*}

\section{Relevant research/expertise}

\section{Relevant academic research}

Papers published on disease/outcome in source research article, median $(95 \% \mathrm{Cl})$

Papers published on treatment/exposure in source research article, median $(95 \% \mathrm{Cl})$

No published papers on disease/outcome or treatment/ exposure in source research article

Research conducted of similar design to source research article

\section{Expertise $\ddagger$}

Academic expertise§

Clinical expertise

Neither academic nor clinical expertise
Independent comments $n=104$

$2(1-5)$

$0(0-1)$

$29(28)$

$48(46)$

$26(25)$

\section{Editorial comments}

$n=21$

$p$ value

$<0.001$

0.02

$2(0-21)$

$1(5)$

0.02

$19(90)$

$<0.001$

Note: $\mathrm{Cl}=$ confidence interval.

*Unless stated otherwise.

†In the 5 years before publication of the source article.

$\ddagger$ Thirty-nine independent commenters and 7 editorialists had both academic and clinical expertise.

$\S$ Published $\geq 5$ papers relevant to the source research article during the 5 years before its publication.

$18(86)$

$10(48)$

$0(0)$ 
the 56 academic conflicts of interest and 11 (33\%) of the 33 financial conflicts of interest were reported in the news stories. Eleven (44\%) of the 25 reported academic conflicts of interest and 2 (18\%) of the 11 reported financial conflicts of interest were explicitly mentioned. Among the editorial comments, none of the 9 academic conflicts of interest and $2(25 \%)$ of the 8 financial conflicts of interest were declared. Both of the declared financial conflicts of interest were explicitly mentioned.

Twenty-three comments in news stories were provided by spokespersons of advocacy organizations (Appendix 2, available at www.cmaj.ca/lookup/suppl/doi:10.1503/cmaj.160538/-/DC1).
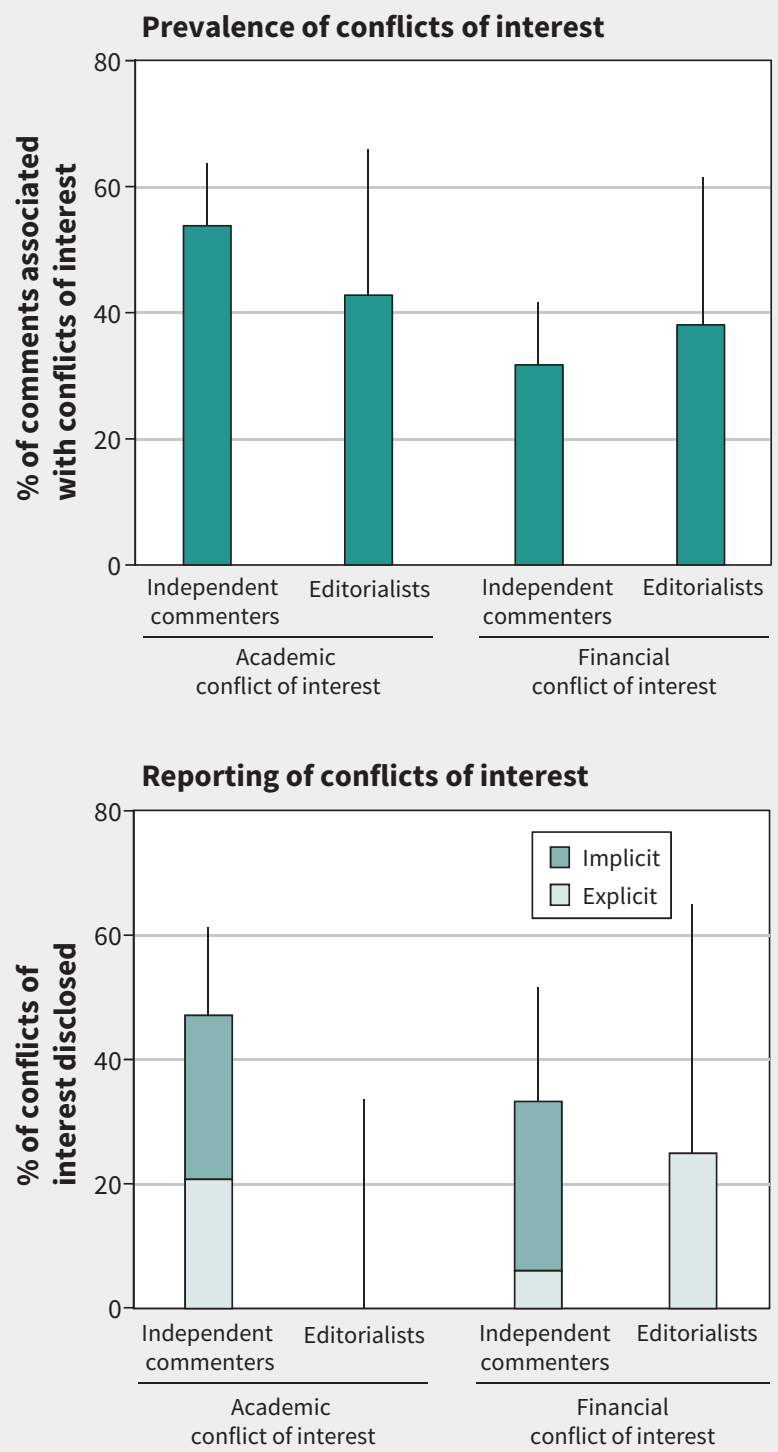

Figure 2: Prevalence and reporting of conflicts of interests. Top panel: Proportions of independent and editorial comments associated with financial or academic conflicts of interests. Bottom panel: Proportions of financial or academic conflicts of interest reported in news stories or editorials: light green bars indicate conflicts of interest stated explicitly, dark green bars indicate implied conflicts of interest. Error bars represent $95 \%$ confidence intervals.
In 6 instances (26\%), the organization in question received sponsorship from a commercial entity with a vested interest relevant to the source research. None of these financial conflicts of interest was disclosed.

\section{Disposition toward research findings}

Figure 3 shows the associations between the findings of the source research, the independent commenters' conflicts of interest and the disposition of their comments toward the study findings. When the independent commenters' academic conflicts of interests were congruent with the findings of the source research, 34 (97\%) of the 35 comments expressed positive views about the study findings, as compared with 3 (16\%) of the 19 comments that expressed positive views when the academic conflicts of interest were not congruent with the research findings $(p<0.001)$.

When the independent commenters' financial conflicts of interests were congruent with the findings of the source research, 13 (95\%) of the 14 comments expressed positive views about the study findings, as compared with $3(17 \%)$ of the 18 comments that expressed positive views when the financial conflicts of interests were not congruent with the research findings. The small sample size precluded meaningful analysis for editorialists.

\section{Interpretation}

Despite recommendations that news stories about health research include comments from independent sources, ${ }^{6}$ only about 1 in 6 stories generated in response to clinical research published in major medical journals included such comments. Our findings

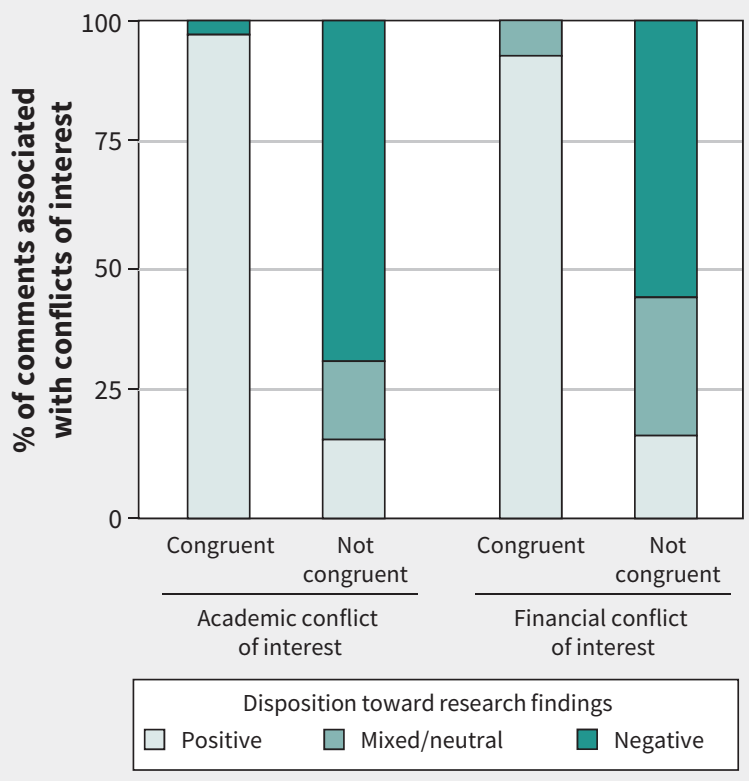

Figure 3: Disposition of independent comments toward study results, according to congruence of associated conflicts of interest with source research findings. The congruence of the academic conflicts of interest of 2 commenters and the financial conflict of interest of 1 commenter with the results of the source research was indeterminate. 
suggest that independent commenters in health news stories often appear to lack expertise or have academic and financial conflicts of interest that are not disclosed, or both. The disposition of comments by independent commenters was strongly associated with the congruence or discordance of commenters' conflicts of interest with the findings of the source research. These observations may be important because media coverage of medical research affects the views and behaviour of the general public, and academic and clinical communities. ${ }^{12-15}$ Readers of news stories would reasonably expect independent commenters to be knowledgeable, and any financial or academic conflicts that might affect interpretation of the work to be explicitly reported. If commenters' conflicts of interest are not reported, it might affect the ability of readers to evaluate the comments, and influence their overall response.

Moynihan and colleagues ${ }^{32}$ reported that $50 \%$ of news stories about research on 3 medications cited at least 1 expert or study with a relevant financial conflict of interest, of which only $40 \%$ were reported. In a review of health news stories at a health journalism website, $46 \%$ did not meet the quality criterion of using an independent source and identifying conflicts of interest, but no analysis of independent commenters was reported. ${ }^{33}$

Although editorials and news stories represent different mechanisms for commenting on clinical research, each fundamentally seeks to describe the nature and importance of the source research. We included editorial comments in our analysis principally as a comparison for comments from independent commenters. It is not surprising that academic conflicts of interest were frequently present for editorialists (about $40 \%$ ), but it is surprising that financial conflicts of interest were equally common and that only a minority were disclosed. All of the journals included in the current analysis require disclosure of financial conflicts.

\section{Limitations}

Some of our analyses considered subjective outcomes, but we assessed each outcome independently and sought consensus in the event of disagreement. Our definitions of expertise were made a priori, but some might disagree with their stringency. Our study was observational, so we cannot infer that the association between the commenters' conflicts of interest and the disposition of their comments toward the source research is causal. Some of the independent commenters were spokespersons for advocacy organizations. Including their comments might have decreased the proportion of commenters with relevant expertise and decreased the prevalence of conflicts of interest. However, the prevalence of financial conflicts of interest among the organizations represented by spokespersons $(23 \%)$ was at least moderate.

\section{Conclusion}

Our findings suggest that independent comments in news coverage of medical research are often neither expert nor independent of academic or financial conflicts of interest. Strategies to improve this aspect of communication of clinical research findings to the wider community might be developed and empirically tested by journalists and commenters.

\section{References}

1. Thompson DF. Understanding financial conflicts of interest. N Engl J Med 1993; 329:573-6.

2. Bekelman JE, Li Y, Gross CP. Scope and impact of financial conflicts of interest in biomedical research: a systematic review. JAMA 2003;289:454-65.

3. Steinbrook R, Lo B. Medical journals and conflicts of interest. J Law Med Ethics 2012;40:488-99.

4. Vineis P, Saracci R. Conflicts of interest matter and awareness is needed. J Epidemiol Community Health 2015;69:1018-20.

5. Relman AS. Dealing with conflicts of interest. N Engl J Med 1984;310:1182-3.

6. Statement of principles of the Association of Health Care Journalists. Columbia (MO): Association of Health Care Journalists. Available: http://healthjournalism. org/secondarypage-details.php?id=56 (accessed 2016 Apr. 19).

7. Author responsibilities - conflicts of interest. Bethesda (MD): International Committee of Medical Journal Editors. Available: www.icmje.org/recommendations/ browse/roles-and-responsibilities/author-responsibilities--conflicts-of-interest. html (accessed 2016 Apr. 19).

8. Guyatt G, Akl EA, Hirsh J, et al. The vexing problem of guidelines and conflict of interest: a potential solution. Ann Intern Med 2010;152:738-41.

9. Loder E, Brizzell C, Godlee F. Revisiting the commercial-academic interface in medical journals. BMJ 2015;350:h2957.

10. Godlee F. Conflict of interest: forward not backward. BMJ 2015;350:h3176.

11. Lenzer J, Hoffman JR, Furberg CD, et al. Ensuring the integrity of clinical practice guidelines: a tool for protecting patients. BMJ 2013;347:f5535.

12. Grilli R, Ramsay C, Minozzi S. Mass media interventions: effects on health services utilisation. Cochrane Database Syst Rev 2002;(1):CD000389.

13. Phillips DP, Kanter EJ, Bednarczyk B, et al. Importance of the lay press in the transmission of medical knowledge to the scientific community. N Engl J Med 1991;325:1180-3.

14. Schwartz LM, Woloshin S. The media matter: a call for straightforward medical reporting. Ann Intern Med 2004;140:226-8.

15. Sharma V, Dowd MD, Swanson DS, et al. Influence of the news media on diagnostic testing in the emergency department. Arch Pediatr Adolesc Med 2003, 157:257-60.

16. Wang MTM, Bolland MJ, Gamble G, et al. Media coverage, journal press releases and editorials associated with randomized and observational studies in high-impact medical journals: a cohort study. PLoS One 2015;10:e0145294.

17. Wang MTM, Bolland MJ, Grey A. Reporting of limitations of observational research. JAMA Intern Med 2015;175:1571-2.

18. van Nood E, Vrieze A, Nieuwdorp M, et al. Duodenal infusion of donor feces for recurrent Clostridium difficile. N Engl J Med 2013;368:407-15.

19. Vimaleswaran KS, Berry DJ, Lu C, et al. Causal relationship between obesity and vitamin D status: bi-directional Mendelian randomization analysis of multiple cohorts. PLoS Med 2013;10:e1001383.

20. Brinkhaus B, Ortiz M, Witt CM, et al. Acupuncture in patients with seasonal allergic rhinitis: a randomized trial. Ann Intern Med 2013;158:225-34.

21. Morin M. Fecal transplants successful in treating intestinal ailment. Los Angeles Times 2013 Jan. 17. Available: http://articles.latimes.com/2013/jan/17/science/ la-sci-fecal-transplant-20130117 (accessed 2016 Nov. 16).

22. Obesity may cause low vitamin D levels. Nursing Times 2013 Feb. 15. Available: https://www.nursingtimes.net/home/behind-the-headlines/obesity-may-cause-low -vitamin-d-levels/5054759.article (accessed 2016 Nov. 16).

23. Coeytaux RR, Park JJ. Acupuncture research in the era of comparative effectiveness research. Ann Intern Med 2013;158:287-8.

24. DeFina LF, Willis BL, Radford NB, et al. The association between midlife cardiorespiratory fitness levels and later-life dementia: a cohort study. Ann Intern Med 2013;158:162-8.

25. Teerlink JR, Cotter G, Davison BA, et al. Serelaxin, recombinant human relaxin-2, for treatment of acute heart failure (RELAX-AHF): a randomised, placebo-controlled trial. Lancet 2013;381:29-39. 
26. Wright JD, Ananth CV, Lewin SN, et al. Robotically assisted vs laparoscopic hysterectomy among women with benign gynecologic disease. JAMA 2013;309:689-98.

27. Mann D. Midlife exercise may help prevent dementia later on. Health 2013 Feb. 5. Available: http://news.health.com/2013/02/05/exercising-at-midlife-may-stave -off-dementia-down-the-road/ (accessed 2016 Nov. 16).

28. Falconi M, Corbett Dooren J. Novartis heart drug shows mixed results. Wall Street Journal 2012 Nov. 6. Available: www.wsj.com/articles/SB10001424052970 204349404578102853568633878 (accessed 2016 Nov. 16).

29. Innes S. Doctors defend use of surgery robots amid study questioning their cost. Arizona Daily Star 2013 Feb. 24. Available: http://tucson.com/news/science /health-med-fit/doctors-defend-use-of-surgery-robots-amid-study-questioning -their/article_dcb1c82f-8838-59d0-a098-10c27c4ebdcc.html (accessed 2016 Nov. 16).

30. de Vet HC, Mokkink LB, Terwee CB, et al. Clinicians are right not to like Cohen's $\kappa$. BMJ 2013;346:f2125.

31. Landis JR, Koch GG. The measurement of observer agreement for categorical data. Biometrics 1977;33:159-74.

32. Moynihan R, Bero L, Ross-Degnan D, et al. Coverage by the news media of the benefits and risks of medications. N Engl J Med 2000;342:1645-50.

33. Schwitzer G. Trying to drink from a fire hose: too much of the wrong kind of health care news. Trends Pharmacol Sci 2015;36:623-7.
Competing interests: Andrew Grey is a shareholder in Auckland Bone Density, a company that provides bone mineral density measurements. All of the authors have coauthored publications on the reporting and dissemination of clinical research findings. Andrew Grey and Mark Bolland have coauthored publications on conflicts of interest in the interpretation of clinical research findings.

This article has been peer reviewed.

Affiliation: Department of Medicine, University of Auckland, Auckland, New Zealand
Contributors: All of the authors contributed to the study design and to the acquisition, analysis and interpretation of data. Andrew Grey drafted the manuscript. All of the authors revised it critically for important intellectual content, approved the final version to be published and agreed to act as guarantors of the work.

Funding: Mark Bolland is the recipient of a Sir Charles Hercus Health Research Fellowship from the Health Research Council of New Zealand and receives research funding from the same organization. Andrew Grey receives research funding from the Health Research
Council of New Zealand and Pharmac, the New Zealand Government's Pharmaceutical Management Agency. These funders had no role in the design or conduct of the study; the collection, management, analysis or interpretation of the data; or the preparation, review or approval of the manuscript.

Accepted: Oct. 27, 2016

Early release: Dec. 19, 2016

Correspondence to: Andrew Grey, a.grey@auckland.ac.nz 